\title{
Autoimmune Thrombocytopenic Purpura, Autoimmune Hemolytic Anemia and Gastric Cancer Appeared in a Patient with Myasthenia Gravis
}

\author{
Nobuo Wakata, Tetsuhito Kiyozuka, Singo Konno, Hiroshi Nakazora, \\ Nobuatsu Nomoto, Hideki Sugimoto and Hiroshi Nemoto
}

\begin{abstract}
We report a case of myasthenia gravis (MG) associated with autoimmune thrombocytopenic purpura (AITP) and autoimmune hemolytic anemia (AIHA), and after that gastric cancer appeared. A 51-year-old man began to suffer from fluctuated muscle weakness in 1985. Muscle weaknesses became exacerbated, and he was admitted to our hospital in 1989. He was diagnosed as MG associated with AITP. After a thymectomy (hyperplasia), prednisolone therapy was started, subsequently his condition was satisfactory. In March 1995, he developed severe anemia and icterus. He was diagnosed as Evans' syndrome (AIHA and AITP) with MG. High-doses of immunoglobulin administration improved the anemia, but thrombocytopenia continued. In November 2002, he suffered marked petechia; the platelet count decreased to 1000/ul. Methylprednisolone pulse therapy and platelet transfusion were started. Gastrofiberscopy was performed and biopsy specimens revealed signet cell-type adenocarcinoma. On December 19, 2002, subtotal gastrectomy and splenectomy were performed. After that, his condition has remained satisfactory, without MG symptoms or thrombocytopenia. This is the first such case report in the literature.
\end{abstract}

Key words: myasthenia gravis, autoimmune thrombocytopenic purpura, autoimmune hemolytic anemia, gastric cancer

(DOI: 10.2169/internalmedicine.45.1496)

\section{Introduction}

Myasthenia gravis (MG) is associated with many types of autoimmune diseases. The coincidence of MG and autoimmune thrombocytopenic purpura (AITP) (1-6) or autoimmune hemolytic anemia (AIHA) (7-11) has only occasionally been reported. While AITP and AIHA are frequently associated with cancer, gastric adenoma is an extremely rare association (12-14). We offer the first report, to the best of our knowledge, of a case of MG associated with AITP and AIHA, and after that gastric cancer appeared.

\section{Case}

A 51-year-old man begun to suffer from muscle weakness of the lower extremities in the middle of 1985. Subsequently, muscle weakness progressed to the upper extremities, leaving the subject unable to wash his face by the end of 1985. Muscle weakness fluctuated but he was able to continue with his duties at work. In 1989, these muscle weaknesses exacerbated, and he was admitted to our hospital. He had never experienced ptosis, diplopia or dysphagia. Manual muscle strength testing revealed 3-4/5 strength in both the upper and lower extremities. The edrophoneum chloride test was positive. The serum anti-acetylcholine receptor antibody titer was $216.5 \mathrm{nmol} / \mathrm{l}$. Repetitive median nerve stimulation testing of musculus abductor pollicis brevis showed decrements in muscle action potential amplitude of $66 \%$ at $3 \mathrm{~Hz}, 63 \%$ at $5 \mathrm{~Hz}$ and $59 \%$ at $10 \mathrm{~Hz}$. He was diagnosed with MG associated with AITP (platelet 7.3-10.8x $\left.10^{4} / \mu \mathrm{l}\right)$. After a thymectomy showing hyperplasia, daily 20

Department of Neurology, Toho University School of Medicine, Oohashi Hospital, Tokyo

Received for publication July 14, 2005; Accepted for publication February 3, 2006

Correspondence to Nobuo Wakata, Department of Neurology, Toho University School of Medicine, Oohashi Hospital, 2-17-6 Oohashi Meguroku, Tokyo 153-8515 


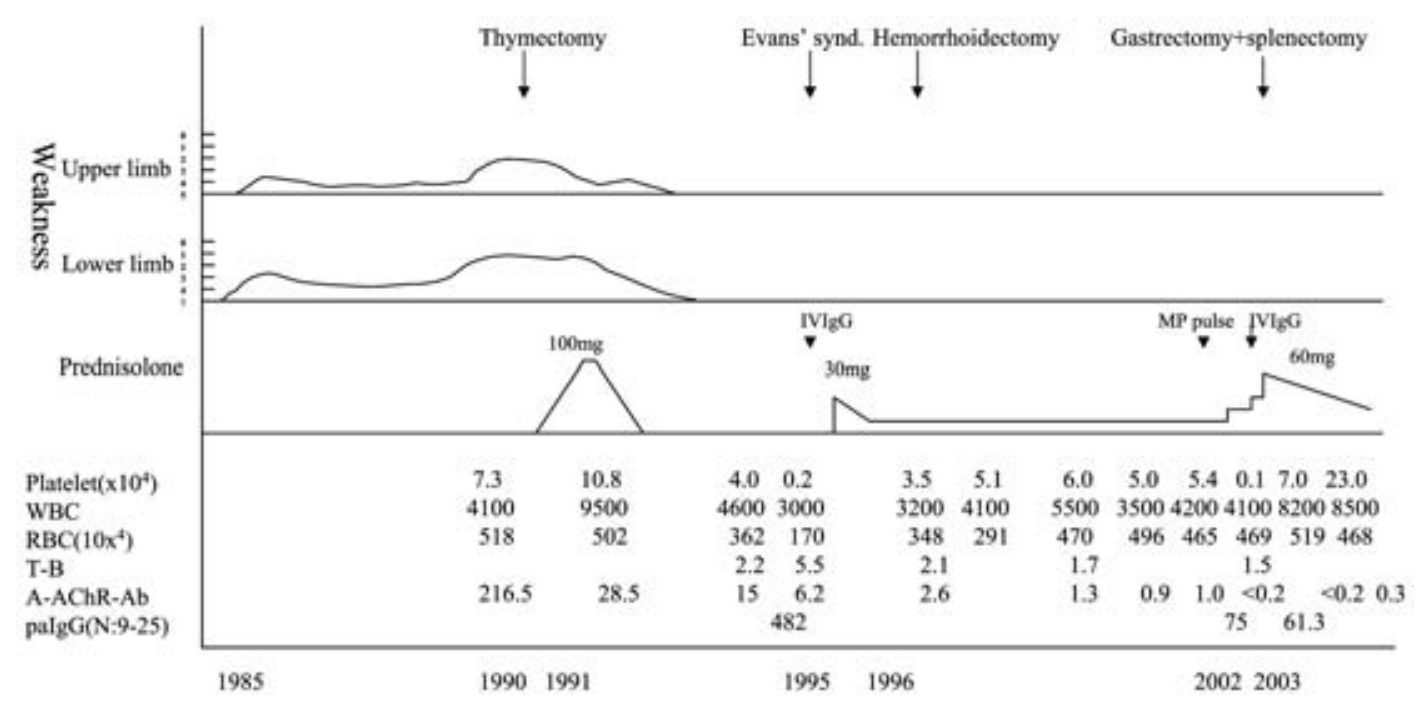

Figure 1. Patient course. WBC: white blood cell, RBC: red blood cell, T-B: total bilirubin, AAChR-Ab: anti-acetylcholine receptor antibody ( $\mathrm{N}<0.2 \mathrm{nmol} / \mathrm{l})$, Evans' synd: Evans' syndome, IVIgG: intra venous immunoglobulin, MP pulse: methylprednisolone puls, paIgG: platelet-associated IgG.

mg prednisolone therapy was started. The dose of prednisolone was gradually increased to $100 \mathrm{mg} /$ day, then gradually decreased and withdrawn in December 1992. After that, his condition was satisfactory without any muscle weakness. In May 1994, laboratory data suggested anemia. In March 1995, he developed severe anemia and icterus. He was readmitted with a diagnosis of Evans' syndrome (AIHA and AITP) with MG. Both direct and indirect Coombs tests were positive; the red blood cell count was $170 \times 10^{4} / \mu 1$ and the white blood cell count was 3000/ $\mu$ l. Severe splenomegaly was detected. Intravenous immunoglobulin $400 \mathrm{mg} / \mathrm{kg}$ was administered for 5 days. Subsequently, laboratory findings improved, but thrombocytopenia continued with platelet counts fluctuating between $6-8 \times 10^{4} / \mu \mathrm{l}$. Fifteen mg prednisolone was administered every other day starting in December 2001. In August 2002, platelet counts fluctuated between 1.6-2.1 $\times 10^{4} / \mu \mathrm{l}$, and the dose of prednisolone was increased to $20 \mathrm{mg}$ every other day. In November 2002, he suffered intra-oral hemorrhage and marked petechia of the lower extremities; the platelet count decreased to $1000 / \mu l$. He was readmitted for severe AITP. Methylprednisolone pulse therapy (1000 mg for 3 days) and 20 units of platelet transfusion were started; subsequently, prednisolone $60 \mathrm{mg} /$ day was started. Platelets increased to $10.7 \times 10^{4} / \mu 1$. Gastrofiberscopy was performed because of gastric complaints. Biopsy specimens revealed signet cell-type adenocarcinoma. On December 19, 2002, subtotal gastrectomy and splenectomy were performed. He was discharged on January 11, 2003 with a platelet count of $24.4 \times 10^{4} / \mu 1$. After that, his condition has remained satisfactory, without MG symptoms or thrombocytopenia [Fig. ]. He is working in usually good health in October 2005.

$\overline{\text { Discussion }}$

Nineteen years ago, the patient suffered from MG with associated AITP. After extended thymectomy and high dose prednisolone administration, MG went into complete remission, but AITP persisted. After 3 years, Evans' syndrome was diagnosed. After an additional 7 years, he developed severe AITP and gastric cancer. Fortunately, the gastric cancer was not advanced, and subtotal gastrectomy with splenectomy was successfully performed. Thrombocytopenia subsequently improved.

MG is often associated with hematological autoimmune disorders such as AITP, pure red cell anemia, pernicious anemia, AIHA and pancytopenia. AITP, AIHA, autoimmune leukopenia and Evans' syndrome may occur in any combination and are associated with other diseases including collagen vascular diseases and malignancies.

MG, AITP and AIHA are disorders caused by failures in autoimmune mechanisms. Combined MG and AITP or AIHA has been infrequently described. The association of AITP (17-19) or AIHA (13-16, 20-22) with malignancy is well known; however, coincident AITP or AIHA and gastric cancer appears to be extremely rare $(12,13,15)$. Inoue et al (13) reported that the most frequent cancer sites associated with AIHA were lung, ovary and colon, and the most highest frequent cancer histological type was adenocarcinoma. Some authors have claimed that cancer and metastasis exacerbate AIHA $(13,16,20,21)$. It has been suggested that mucin produced by the neoplasm plays an important role in the development of immune hemolysis $(16,20,22)$; however, in the patient there was no evidence of malignancy when AIHA was diagnosed. In the present case, early stage gastric cancer exacerbated AITP. In an immunodeficient host 
erythrocytes and platelets may produce tumorigenic substances, or, alternatively anti-erythrocyte and anti-platelet auto-antibodies may facilitate the development of a malignant tumor. We could not determine which therapy was effective for AITP, because the patient underwent simultaneous gastrectomy and splenectomy.
In summary, the coincidence of MG and extrathymic tumors has been reported, and the risk of these associations has been described in 1.7-9\% (23-30) of MG patients. In the present case, however, malignancy appears to have been associated with autoimmune deficiencies such as AITP rather than MG.

\section{References}

1. Segal BM, Weintraub MI. Hashimoto's thyroiditis, myasthenia gravis, idiopathic thrombocytopenic purpura. Ann Int Med 85: 761-763, 1976.

2. Veenhoven WA, Oosterhuis HJ, van der Schans GS. Myasthenia gravis and Werlhof's disease. Acta Med Scand 206: 133-135, 1979 .

3. Anderson MJ, Woods VL, Tani P, Lindstrom JM, Schmidt D, McMillian R. Antibodies to platelet glycoprotein IIb/IIIa and to the acetylcholine receptor in a patient with chronic idiopathic thrombocytopenic purpura and myasthenia gravis. Ann Int Med 100: 829-831, 1984.

4. Jansen PH, Reiner WO, de Vaan G, Reekers P, Vingerhoets DM, Gabreel FJ. Effect of thymectomy on myasthenia gravis and autoimmune thrombocytopenic purpura in a 13-year-old girl. Eur J Pediat 146: 687-589, 1987.

5. Matsuno S, Tamaoka A, Yoshizawa K, Watanabe M, Shoji S. A case with myasthenia gravis (MG) after splenectomy for idiopathic thrombocytopenic purpura (ITP): possible effects of thymectomy on autoantibodies. J Med 31: 327-332, 2000.

6. Ho SL, Shah M, Williams AC. Idiopathic thrombocytopenic purpura and autoimmune thyroiditis in a patients with myasthenia gravis. Muscle Nerve 15: 966-967, 1992.

7. Halperin IC, Minogue WF, Komninos ZD. autoimmune hemolytic anemia and myasthenia gravis associated with thymoma. N Eng J Med 275: 663-664, 1966.

8. Cohen SM, Waxman S. Myasthenia gravis, chronic lymphocytic leukemia and autoimmune hemolytic anemia. Arch Intern Med 120: 717-720, 1967.

9. Durance RA. Myasthenia gravis, rheumatoid arthritis, vitiligo, and autoimmune hemolytic anemia. Proc roy Soc Med 67: 61-67, 1971.

10. Kornfeld P, Glass J, Papatestas AE, Horowitz S, Matta R, Genkins G. Case report. Thymectomy-induced remission of acquired autoimmune hemolytic anemia in an adult with myasthenia gravis. Am J Med Sci 277: 111-116, 1979.

11. Kameoka J, Endo K, Sugawara T, et al. Autoimmune hemolytic anemia and myasthenia gravis. Jpn J Med 30: 330-332, 1991.

12. Frumin AM, Mendell TH, Merane DR. Hematologic manifestation of metastatic gastric malignancy. Gastroenterology 27: 183-188, 1954

13. Inoue $\mathrm{Y}$, Kaku $\mathrm{K}$, Kaneko $\mathrm{T}$, Matsumoto N. Autoimmune hemolytic anemia and gastric cancer: case report and review of the literature. Acta Haematol Jpn 46: 836-841, 1983.

14. Yonekura S, Nagao T, Arimori S, Miyaji M, Ogoshi K, Tsutsumi Y. Evans' syndrome associated with gastric plasmacytoma: case report and a review of the literature. Jpn J Med 29: 312-515, 1990.
15. Larsen JR, Becher JW. Fatal fulminant autoimmune haemolytic anaemia associated with Tolmetin use and gastric carcinoma. Drug Safety 8: 169-178, 1993.

16. Miura AB, Shibata A, Akihama T, et al. Autoimmune hemolytic anemia associated with colon cancer. Cancer 33: 111-114, 1974.

17. Demirer T, Celebi H, Arat M, et al. Autoimmune thrombocytopenia in a patient with small cell lung cancer developing after chemotherapy and resolving following autologous peripheral blood stem cell transplantation. Bone marrow Transplant 24: 335-337, 1999.

18. Porrata LF, Alberts S, Hook C, Hanson CA. Idiopathic thrombocytopenic purpura associated with breast cancer: a case report and review of the current literature. Am J Clin Oncol 22: 411-413, 1999.

19. Ustun C, Dainer P, Hendrick L, Brucker L, Burgess R. Association of breast cancer and immune thrombocytopenic purpura. South Med J 95: 1335-1337, 2002.

20. Spira RYA, Lynch WG. Autoimmune hemolytic anemia and carcinoma: an unusual association. Am J Med 67: 753-758, 1979.

21. Wartman J, Rosse W, Lugue G. Cold agglutinin autoimmune hemolytic anemia in non-hematologic malignancies. Am J Hematol 6: 275-283, 1979.

22. Yam LT, Rudzki G, Rush S, Leihold SL. Ovarian neoplasm associated with autoimmune hemolytic anemia. Am J Obst Gynec 95: 207-211, 1966

23. Papatestas AE, Osserman KE, Kark AE. The relationship between thymus and oncogenesis: A study of the incidence of non thymic malignancy in myasthenia gravis. Br J Cancer 25: 635-645, 1971.

24. Vessey MP, Doll R, Noman-Smith B, Hill ID. Thymectomy and cancer: A further report. Br J Cancer 39: 193-195, 1979.

25. Goulon M, Estournet B, Tulliez M. Myasthenia gravis and associated disease. Inter J Neurology 14: 61-72, 1980.

26. Oosterhuis HJ. Observations of the natural history of myasthenia gravis and the effect of thymectomy. Ann NY Acad Sci 377: 678690, 1981.

27. Monden Y, Uyama T, Kimura S, Taniki T. Extrathymic malignancy in patients with myasthenia gravis. Eur J Cancer 27: 745747, 1991.

28. Masaoka A, Yamakawa $\mathrm{Y}$, Niwa $\mathrm{H}$, et al. Thymectomy and malignancy. Eur J Cardio-thorac Surg 8: 251-253, 1994.

29. Ben Hur T, Lossos A, Abramsky O, Argov Z. Extrathymic tumor in patients with myasthenia gravis. Neurology $\mathbf{4 5}$ (suppl 4): A353, 1995.

30. Evoli A, Batocchi AP, Tonali P, Marciano M. Risk of cancer in patients with myasthenia gravis. NY Acad Sci 841: 742-745, 1998.

(C) 2006 The Japanese Society of Internal Medicine http://www.naika.or.jp/imindex.html 